Jurnal Pendidikan Sosial Keberagaman

Print-ISSN 2355-4622 Online-ISSN 2622-9021

Vol. 6, No. 1, Oktober-Maret 2019, hh. 27-35

https://juridiksiam.unram.ac.id/index.php/juridiksiam

\title{
PENGARUH PENERAPAN MODEL PEMBELAJARAN MINDMAPPING JENIS LABA-LABA (SPIDER CONCEPT MAP)TERHADAP PEMAHAMAN KONSEP SISWA KELAS VIIPADA MATA PELAJARAN PPKn DI SMPN 3 LABUAPI
}

\author{
Riya Reza ${ }^{1}$, Ismail ${ }^{2}$, Yuliatin ${ }^{3}$ \\ ${ }^{1}$ Mahasiswa prodi PPKn, ${ }^{23}$ Dosen Jurusan Pendidikan IPS \\ Fakultas Keguruan dan Ilmu Pendidikan Universitas Mataram \\ Email: ismail.fkipgmail.com
}

\begin{abstract}
ABSTRAK
Tujuan penelitian ini adalah untuk mengetahui ada tidaknya pengaruh penerapan model pembelajaranMind Mapping jenis laba-laba (spider concept map) terhadap pemahaman konsep siswa kelas VII pada mata pelajaran PPKn di SMP Negeri 3 Labuapi. Penelitian ini merupakan penelitian Quasi Eksperimen dengan nonequivalen control group pretest-posttest. Instrumen yang digunakan dalam penelitian ini adalah test bentuk pilihan ganda sebanyak 20 item untuk mengukur pemahaman konsep siswa. Data hasil pemahaman konsep siswa diambil menggunakan test pilihan ganda yang sudah memenuhi persyaratan instrumen penelitian. Hasil penelitian menunjukkan bahwa $t_{\text {hitung }}(2,321)^{-} t_{\text {tabel }}(2,000)$ pada taraf signifikan $5 \%$, artinya hasil penelitian menunjukkan bahwa ada pengaruh model pembelajaranmind mapping jenis laba-laba (spider concept map) terhadap pemahaman konsep siswa pada mata pelajaran PPKn di SMP Negeri 3 Labuapi.
\end{abstract}

Kata Kunci: Mind Mapping jenis laba-laba (spider concept map), pemahaman konsep

\begin{abstract}
The purpose of this study was to determine whether or not the effect of applying the spider mind mapping learning model toward understanding the concept of the elerenth grade students on civic education subjects at SMPN 3 Labuapi. This research was a quasiexperimental with non-equivalent control group pretestposttest. The instrument used was 20 multiplechoice test items to measure student's conceptual understanding. Data from the conceptual understanding of student's taken using multiple choice tests that have met the requirements of the research instruments. The result of the study showed that $t_{\text {count }}(2,321) t_{\text {table }}(2,000)$ at a significant level 0f 5\% means that the results of the study showed that there were influences of spider mind mapping learning models on student's conceptual understandingainc education subjects at SMPN 3 Labuapi.
\end{abstract}

Keywords:Mind Mapping type of spider concept map, understanding of concept. 
Vol. 6 No. 1, Oktober-Maret 2019, hh. 27-35

\section{PENDAHULUAN}

Pendidikan Pancasila dan Kewarganegaraan (PPKn)merupakan mata pelajaran wajib yang harus dipelajari di setiap jenjang pendidikan baik ditingkat dasar maupun menengah atas, baik sekolah negeri, swasta maupun sederajat. Samsuri (2011:18) menyatakan bahwa "Pendidikan Kewarganegaraan merupakan upaya pendagogis pembentukan watak warga negara yang baik, yakni memiliki kemampaun memahami konsep untuk bertindak atau tidak bertindak dalam urusan publik maupun privat". Pengalaman belajar akan diperolehsiswa ketika pembelajaran lebih banyakmelibatkan aktivitas siswa dalam proses pembelajaran.Dengan kata lain, menurut Westwood (2008:14) bahwa "siswa sebagai pusat pembelajaran". Siswa didoronguntuk aktif secara mental sehingga dapat mengkonstruksidan mengembangkan pengetahuannyasendiri.Pemahaman konsep menjadi elemen kunci dari PPKn yang merupakan bagianpenting dalam pembelajaran di sekolah yang berpengaruh terhadap sikap siswa. Mata pelajaran PPKn penting untuk di pelajari sebab mengacu kepada nilai-nilai positif khususnya untuk mengembangkan pemahaman konsep pembelajaran siswa.

Tujuan pembelajaran Pendidikan Pacasila dan Kewarganegaraan yang harus mengarahkan peserta didik untuk cedas dalam memahami materi-materi dalam pembelajaran PPKn. Hal tersebut telah termuat dalam buku pegangan guru sebagai pedoman pelaksanaan kegiatan pembelajaran dalam kelas, menegaskan bahwa:

mata pelajaran Pendidikan Pancasila dan Kewarganegaraan mempunyai tujuan; (1) peserta didik mampu menampilkan karakter yang mencerminkan penghayatan, pemahaman, dan pengamalan nilai dan moral Pancasila secara personal dan sosial, (2) memiliki komitmen konstitusional yang ditopang oleh sikap positif dan pemahaman utuh tentang Undang-Undang Dasar Negara Republik Indonesia Tahun 1945, (3) berpikir secara kritis, rasional, dan kreatif serta memiliki semangat kebangsaan dan cinta tanah air yang dijiwai oleh nilai-nilai Pancasila, Undang Undang Dasar Negara Republik Indonesia Tahun 1945,semangat Bhinneka Tunggal Ika, dan komitmen Negara Kesatuan Republik Indonesia, dan (4) berpartisipasi secara aktif, cerdas, dan bertanggung jawab sebagai anggota masyarakat, tunas bangsa, dan warga negara sesuai dengan harkat dan martabatnya sebagai makhluk ciptaan Tuhan Yang Maha Esa yang hidup bersama dalam berbagai tatanan sosial Budaya (Kemendikbud, 2016: 5).

Untuk dapat membantu siswa mencapai Kompetensi Dasar guru tentunya memegang peran sangat penting Hal ini mengingat berbagai peran yang di emban oleh guru yakni sebagai fasilitator, mediator, dan motivator bagi siswa. Dengan demikian, guru tentunya tidak hanya sekedar mampu menguasai materi ajar saja, tetapi harus mampu memilih dan menggunakan metode pembelajaran yang tepat dan menarik. sehingga dapat memudahkan siswa mencapai kompetensi yang diharapkan. Hal ini sesuai dengan pendapat Djamarah (2012:31), bahwa guru dituntut untuk memiliki kemampuan mengembangkan kreatifitasnya dalam mengajar, sehingga dalam proses pembelajaran terjadi interaksi positif antara siswa dengan guru, dan antara siswa 
dengan siswa secara efektif. Keberhasilan pembelajaran yang dimaksud ditunjukkan dengan semakin meningkatnya kemampuan pemahaman konsep pembelajaran siswa.

Berdasarkan kondisi sebagaimana di atas, diperlukan metode pembelajaran yang tepat untuk mengatasi permasalahan tersebut antara lainmetode pembelajaranMind Mappingjenis laba-laba (spider concept map). Adapun yang dimaksud dengan model mind mapping Menurut Aris Shoimin (2014: 105), "Mind Mappingatau pemetaan pikiran adalah teknik pemanfaatan seluruh otak dengan menggunakan citra visual dan prasarana grafis lainnya untuk membentuk kesan”. Sedangkan menurut Michalko dalam Tony Buzan (2013: 2), "Mind Mappingadalah alternatif pemikiran keseluruhan otak terhadap pemikiran linear. Mind Mappingmenggapai ke segala arah dan menangkap berbagai pikiran dari segala sudut”.

Adapun beberapa keunggulan dari model pembelajaran mind mapping jenis laba-laba (spider concept map) yakni: (1) dapat meningkatkan kinerja manajemen pengetahuan; (2) memicu kreativitas, sederhana dan mudah dikerjakan; (3) menarik dan mudah tertangkap mata; (4) serta dapat melihat sejumlah besar data dengan mudah. Namun mind mapping jenis laba-laba (spider concept map) memiliki kekurangan yaitu ketika mengaitkan empat hal sekaligus sehingga membuat mind mapping hanya akan dipahami oleh pembuat, sementara itu orang lain yang membaca butuh waktu cukup lama untuk mempelajarinya karena dibantu satu kata kunci tiap garisnya. Maka hendaknya kata kunci dibantu atau ditambahi dua atau lebih kata keterangannya.

Penelitian mengenai model pembelajaran mind mappingini pernah dilakukan oleh beberapa peneliti sebelumnya, diantaranya penelitian yang dilakukan oleh Adawiah (2017).Hasil penelitiannya menunjukkan bahwa pengaruh penerapan model pembelajaran mind mapping dapat mempengaruhi hasil belajar siswa. Hasil kajian dari jurnal Hendawati dkk (2018:113-124) membuktikan bahwa penggunaan model pembelajaran mind mapping terhadap pemahaman konsep dapat meningkat dibandingkan dengan hasil belajar siswa yang menggunakan strategi pemebelajaran Peer Lessons.

\section{METODE PENELITIAN}

Pendekatan yang digunakan dalam penelitian ini adalah pendekatan kuantitatif dengan jenis penelitian Quasi Eksperiment dengan rancanganNon-Equivalent Control Group Pretest-Posttest.Sukmadinata (2011: 59) mengatakan bahwa jenis penelitian Quasi Experiment(eksperimen semu)variabel yang ada tidak dikontrol secara keseluruhan, melainkan variabel yang dipandang paling dominan yang dikontrol dan pengontrolannya pun tidak sepenuhnya disamakan tetapi dipasangkan antara kelas kontrol dan kelas eksperimen setelah dilakukan penyepadanan. Design penelitian yang digunakan adalah Non-Equivalent Control Group PretestPosttest.Pada rancangan penelitian ini terdapat enam kelas yang digunakan untuk penelitian, tetapi dipilih dua kelas sebagai sampelyaitu satu kelas sebagai kelas eksperimen dan satu kelas sebagai kelas kontrol.Dapat dilihat pada tabel di bawah ini: 
Vol. 6 No. 1, Oktober-Maret 2019, hh. 27-35

Tabel 1. Nonequivalen Control Group Pretest-Posttest

\begin{tabular}{cccc}
\hline Kelompok & Pre-test & Perlakuan & Post-test \\
\hline Eksperimen & $\mathrm{O}_{1}$ & $\mathrm{X}$ & $\mathrm{O}_{2}$ \\
\hline Kontrol & $\mathrm{O}_{1}$ & - & $\mathrm{O}_{2}$ \\
\hline
\end{tabular}

Berdasarkan gambar 1, kelas eksperimen dikenai variabel perlakuan model pembelajaranMind Mapping jenis Laba-Laba (Spider Concept Map) dan kelas kontrol tidak dikenai perlakuan dengan jangka waktu yang sama dengan kelas eksperimen. Kemudian, keenam kelas tersebut dikenai pengukuran yang sama. Perbedaan kemampuan pemahaman konsep siswa yang timbul dianggap bersumber dari variabel perlakuan. Pada akhir proses pembelajaran diberikan post-tes kepada kelas kontrol dan kelas eksperimen dengan menggunakan instrumen yang sama untuk mengetahui ada tidaknya pengaruh perlakuan terhadap pemahaman konsep siswa pada Mata Pelajaran PPKn di SMPN 3 Labuapi.

Instrumen pengumpulan data pemahaman konsep siswa pada Mata Pelajaran PPKn menggunakan instrumen test berupa pilihan ganda yang telah dilakukan uji validitas, reliabilitas, tingkat kesukaran, dan daya pembeda.hasil pengujian menunjukkan bahwa instrumen yang digunakan telah memenuhi kriteria instrumen yang baik.

Data yang diperoleh berdasarkan hasil penelitian, kemudian dianalisis dengan metode yang dikembangkan berdasarkan kajian penelitian kuantitatif. Analisis data menggunakan uji persayaratan analisis mencakup uji homogenitas dan uji normalitas data. Setelah itu menggunakan uji hipotesis dengan menggunakan uji $\mathrm{T}$.

\section{HASIL DAN PEMBAHASAN}

\section{Hasil}

Deskripsi hasil ini mencakup hasil uji persyaratan analisis dan uji hipotesis.

\section{Uji Persyaratan Analisis}

Uji persyaratan analisis terdiri dari uji normalitas dan uji homogenitas. Uji homogenitas digunakan untuk menyamakan atau menghomogenkan kemampuan awal kedua kelompok sampel dengan menggunakan rumus uji-F. Sedangkan uji normalitas ini dilakukan bertujuan untuk mengetahui data berdistribusi normal atau tidak dengan menggunakan Chi Kuadrat. Hasil uji homogenitas tes awal dan tes akhir pada kelompok kelas eksperimen dan kelas kontrol dapat dilihat pada tabel 1 berikut:

Tabel 2. Hasil uji homogenitas tes awal

\begin{tabular}{cccccccc}
\hline Kelas & $\mathbf{N}$ & $\overline{\boldsymbol{x}}$ & $\boldsymbol{S}$ & $\boldsymbol{S}^{\mathbf{2}}$ & $\boldsymbol{F}_{\text {hitung }}$ & $\boldsymbol{F}_{\text {tabel }}$ & Keterangan \\
\hline Eksperimen & 32 & 53,906 & 10,529 & 110,862 & \multirow{2}{*}{1,0} & 2,04 & \multirow{2}{*}{ Homogen } \\
\cline { 1 - 5 } Kontrol & 32 & 53,281 & 10,548 & 111,265 & & & \\
\hline \multicolumn{2}{l}{ Sumber:pengolahan data primer } & & & & &
\end{tabular}


Berdasarkan Tabel 1 di atas, dapat ditarik kesimpulan bahwa $F_{\text {hitung }}(1,0)<\mathrm{F}_{\text {tabel }}(2,04)$ pada taraf signifikan 5\%, maka kedua sampel memiliki varian yang homogen. Artinya bahwa analisis dengan uji parametrik memenuhi syarat.

Tabel 3. Hasil uji homogenitas tes akhir

\begin{tabular}{|c|c|c|c|c|c|c|c|}
\hline Kelas & $\mathbf{N}$ & $\bar{x}$ & $S$ & $S^{2}$ & $F_{\text {hitung }}$ & $F_{\text {tabel }}$ & Keterangan \\
\hline Eksperimen & 32 & 72,97 & 7,17 & 51,386 & \multirow{2}{*}{1,13} & \multirow{2}{*}{2,04} & \multirow{2}{*}{ Homogen } \\
\hline Kontrol & 32 & 61,41 & 6,75 & 45,539 & & & \\
\hline
\end{tabular}

Berdasarkan Tabel 2 di atas, dapat ditarik kesimpulan bahwa $F_{\text {hitung }}(1,13)<F_{\text {tabel }}(2,04)$ pada taraf signifikan 5\%, maka kedua sampel memiliki varian yang homogen. Artinya bahwa analisis dengan uji parametrik memenuhi syarat.

Setelah dilakukan ujji homogenitas, maka digunakan uji normalitas data untuk mengetahui data berdistribusi normal atau tidak.

\section{Uji Normalitas}

Tabel 4. Uji Normalitas Data Akhir Siswa

\begin{tabular}{cccc}
\hline Kelas & $\boldsymbol{\chi}_{\text {hitung }}^{2}$ & $\boldsymbol{\chi}_{\text {tabel }}^{2}$ & Keterangan \\
\hline Eksperimen & 9,5 & \multirow{2}{*}{11,070} & \multirow{2}{*}{ Normal } \\
\hline Kontrol & 3,0 & &
\end{tabular}

Berdasarkan Tabel 3 di atas, terlihat bahwa pada kelas eksperimen $\chi_{\text {hitung }}^{2}(9,5)<\chi_{\text {tabel }}^{2}(11,070)$ dan pada kelas kontrol $\chi_{\text {hitung }}^{2}(3,0)<\chi_{\text {tabel }}^{2}(11,070)$. Hal ini menunjukkan bahwa data tes akhir pada kedua kelompok kelas berdistribusi normal.

\section{Uji Hipotesis}

Hasil analisis uji hipotesis data terhadap pemahaman konsep siswa pada mata pelajaran PPKn dapat dilihat pada Tabel 4sebagai berikut:

Tabel 5. Analisis Hipotesis Posttest

\begin{tabular}{ccccccc}
\hline Kelas & $\mathbf{N}$ & $\overline{\boldsymbol{x}}$ & $\boldsymbol{S}$ & $\boldsymbol{S}^{\mathbf{2}}$ & $\boldsymbol{t}_{\text {hitung }}$ & \multirow{2}{*}{$\boldsymbol{t}_{\text {tabel }}$} \\
\hline Eksperimen & 32 & 72,97 & 7,17 & 51,386 & \multirow{2}{*}{2,321} & \multirow{2}{*}{2,000} \\
\cline { 1 - 5 } Kontrol & 32 & 58,59 & 6,98 & 48,8 & & \\
\hline Sumber:pengolahan data primer & \multicolumn{3}{l}{} & &
\end{tabular}

Berdasarkan Tabel 4 uji t diperoleh nilai $t_{\text {hitung }}$ pada kelas eksperimen dan kelas kontrol $=2,321$ dan tabel $=2,000$, dengan $\mathrm{dk}=32+32-2$ sehingga thitung $>$ tabel pada taraf signifikan $5 \%$. Artinya hipotesis yang diajukan dalam penelitian ini yaitu ada pengaruh penerapan model pembelajaran Mind Mapping jenis LabaLaba (Spider Concept Map) terhadap pemahamn konsep siswa kelas VII di SMPN 3 Labuapi. 


\section{Uji $N$-Gain}

Setelah dilakukan uji hipotesis selanjutnya dilakukan uji $\mathrm{N}$-Gain untuk mengetahui selisih atau perbedaan nilai rata-rata antara hasil Pre test dan Post test dari kelas eksperimen dan kelas kontrol. Berdasarkan hasil pengolahan uji $\mathrm{N}$-Gain dari nilai rata-rata peserta didik diperolah sebagai berikut:

Tabel 6. Hasil uji $\mathbf{N}$-Gain tes awal dan tes akhir kelas eksperimen dan kelas kontrol

\begin{tabular}{ccccc}
\hline Kelas & $\begin{array}{c}\text { Rata-rata } \\
\text { tes akhir }\end{array}$ & $\begin{array}{c}\text { Rata-rata } \\
\text { tes awal }\end{array}$ & N-Gain & Kategori \\
\hline Eksperimen & 72,97 & 53,906 & 0,39 & Sedang \\
\hline Kontrol & 61,41 & 53,281 & 0,17 & Rendah \\
\hline Sumber:pengolahan data primer & & &
\end{tabular}

Berdasarkan Tabel 5 terlihat bahwa hasil uji $N$-Gain kelas eksperimen adalah 0,39 dengan kategori sedang dan hasil uji $\mathrm{N}$-Gain kelas kontrol adalah 0,17 dengan kategori rendah. Artinya bahwa pemahaman konsep siswa menggunakan model pembelajaran Mind Mapping jenis laba-laba (spider concept map)lebih besar dibandingkan dengan pemahaman konsep siswa yang menggunakan model pembelajaran konvensional.

\section{PEMBAHASAN}

Dalam penelitian ini Siswa kelas eksperimen menerima perlakuan berupa model pembelajaran Mind Mapping jenis laba-laba (Spider Concept Map) sedangkan siswa pada kelas kontrol menerima perlakuan berupa model pembelajaran kovensional atau ceramah dan penugasan saja yang biasa digunakan oleh guru pada umumnya.

Hasil belajar yang diukuradalah hasil belajar pemahaman konsep siswa dalam mata pelajaran PPKn dengan menggunakan intrumen soal berupa pilihan ganda pada materi pembelajaran "Norma yang berlaku dalam masyarakat". Sebelum menerima perlakuan, kelas eksperimen dan kelas kontrol diberikan tes awal atau pretest terlebih dahulu untuk melihat kemampuan awal kedua kelompok tersebut.data hasil penelitian menunjukkan untuk tes awal atau pre test, diperoleh rata-rata nilai kelas eksperimen yaitu 53,906 dan kelas kontrol yaitu 53,281. Nilai rata-rata yang diperoleh dari kedua kelompok tersebut menunjukkan bahwa hasil kemampuan pemahaman konsep sebelum menerima perlakuan hampir sama, karena belum memahami materi soal yang diberikan pada tes awal atau pre test.

Hasil tes akhir untuk pemahaman konsep siswa pada kedua kelompok sampel setelah diberikan perlakuan menunjukkan bahwa pemahaman konsep siswa pada kedua kelompok tersebut mengalami perubahan. Rata-rata nilai tes akhir siswa kelas eksperimen adalah 72,97 dan rata-rata tes akhir untuk kelas kontrol adalah 61,41. Secara keseluruhan, siswa yang menerima perlakuan berupa model pembelajaran Mind Mapping jenis laba-laba(spider concept map) menunjukkan perubahan nilai yang lebih tinggi dibandingkan dengan kelas kontrol yang tidak menerima perlakuan model pembelajaran Mind Mapping jenis labalaba(spider concept map). 
Hasil penelitian di atas menunjukkan bahwa pemahaman konsep siswa kelas eksperimen lebih baik dari pada kelas kontrol hal ini dimungkinkan mengingat model pembelajaran Mind Mapping jenis labalaba(spider concept map) adalah model pembelajaran yang dapat mengembangkan kreatifitas, keaktifan dan daya hafal siswa dalam mencapai tujuan pembelajaran.Dalam hal ini siswa akan lebih aktif dan kreatif untuk mencari tahu dan menemukan informasi-informasi yang belum pernah mereka ketahui atau masih dipertanyakan kebenaran dari informasi yang mereka dapatkan dengan demikian maka akan memudahkan siswa untuk menghafal materi yang didapatkan Dengan cara yang sistematis dari metode pembelajaran Mind mapping jenis laba-laba(spider concept map) akan mengarahkan siswa secara tuntas memahami suatu materi pembelajaran dan dapat menciptakan suasana pembelajaran menjadi lebih menarik dalam bentuk pertanyaanpertanyaan tertentu.

Dengan demikian maka siswa akan mudah mengingat materi yang diajarkan sehingga hasil belajarnya akan meningkat. Hal ini tentunya sejalan dengan pendapat Tapantoko (2011:33) bahwa model pembelajaranMind Mapping jenis laba-laba(spider concept map) lebih menekankan pada keaktifan dan kegiatan kreatif siswa, sehingga akan meningkatkan daya hafal dan pemahaman konsep siswa yang kuat. Pembelajaran dengan modelMind Mappingjenis laba-laba (spider concept map)adalah pembelajaran yang dirancang agar siswa memiliki keterampilan berpikir kreatif serta suatu model yang dapat membantu siswa untuk menghubungkan suatu konsep-konsep yang penting.

Selain itu adanya peningkatan pemahaman konsep siswa pada materi norma dengan menggunakan model pembelajaran mind mapping jenis laba-laba (spider concept map) ini dimungkinkan karena melalui pemahaman konsep siswa lebih mudah menyiapkan urutan pembelajaran dengan mengacu pada peta konsep,siswa lebih mengerti keterkaitan antara konsep yang dipelajari. Hal ini sesuai dengan pendapatAusubel (1968) yang menegaskan bahwa diantara manfaat-manfaat dari model mind mapping jenis laba-laba (spider concept map) adalah sebagai berikut: (a)Lebih mudah menyiapkan urutan pembelajaran dengan mengacu pada peta konsep yang disesuaikan dengan pengalamannya;(b)Siswa mengerti keterkaitan antara konsep yang akan dipelajari dan akan lebih mudah merangkum setelah selesai pembelajaran;(c)Siswa akan lebih kuat memorinya dan akan lebih mudah mengaplikasikan konsep-konsep yang telah dipelajari.

Hasil penelitian di atas didukung oleh penelitian terdahulu diantaranya oleh Siti marhamah rabiatul adawiah (2017) menunjukkan bahwa model pembelajaran Mind Mapping dapat mengembangkan hasil belajar siswa pada Mata Pelajaran PPKn di SMP Negeri 1 Batulayar, hasil kajian lain dari artikel dari jurnal Hendawati dkk (2018:113-124) membuktikan bahwa penggunaan model pembelajaran mind mapping terhadap pemahaman konsep dapat meningkat dibandingkan dengan hasil belajar siswa yang menggunakan strategi pemebelajaran Peer Lessons.Nurfitrianipada tahun 2013menunjukkan bahwa pengaruh penggunaan 
Vol. 6 No. 1, Oktober-Maret 2019, hh. 27-35

metode pembelajaran mind mapping bisa meningkatkan kemampuan pemahaman konsep pembelajaran siswa dalam mencapai KKM matematika.

\section{SIMPULAN}

Berdasarkan hasil perhitungan pengujian hipotesis dengan uji-t pada kelas VII A sebagai kelas eksperimen diperoleh $t_{\text {hitung }}=2,321, t_{\text {table }}=2,000$ dengan $\mathrm{dk}=32+32-2=61$ pada taraf signifikansi $5 \%$ sehingga nilaithitung $>t$ tabel yaitu 2,321 $>2,000$, maka dapat dinyatakan hipotesis penelitian diterima yang berarti bahwa ada pengaruh yang signifikan penerapan metode pembelajaran mind mapping jenis laba-laba (spider concept map) terhadap pemahaman konsep siswa pada mata pelajaran PPKn di SMP Negeri 3Labuapi.

\section{UCAPAN TERIMAKASIH}

Ucapan terimakasih disampaikan kepada Jurusan IPS FKIP Universitas Mataram dan Dewan Redaksi Jurdiksiam yang menfasilitasi dalam penelitian dan publikasi hasil kajian ini.

\section{DAFTAR PUSTAKA}

Buzan, T. (2010). Buku Pintar Mind Mapping. Jakarta: PT. Gramedia.

Darmadi, Hamid. 2011. Metode Penelitian Pendidikan. Bandung: Alfabeta

Darmadi. 2017. Pengembangan Model dan Metode Pembelajaran dalam Dinamika Belajar Siswa. Yogyakarta: Depublish.

Hendawati dkk dalam jurnalnya (2018:113-124). Pengaruh penggunaan model

Huda, Miftahul. (2016). Model-Model Pengajaran dan pembelajaran. $\quad$ Yogyakarta: Pustaka pelajar

Karim, A. 2011. Penerapan metode penemuan terbimbing dalam pembelajaran

Matematika untuk meningkatkan pemahaman konsep dan kemampuan berpikir kritis siswa sekolah dasar.Jurnal Pendidikan.

Pembelajaran mind mapping terhadap pemahaman konsep siswa.

Sagala, S. (2006). Konsep dan Makna Pembelajaran. Bandung: Alfabeta.

Sahidu, Chairunisyah. 2013. Penilaian Hasil Belajar. Mataram: Arga Puji Press.

Samsuri. 2011. Pendidikan Kewarganegaraan sebagai Wahana Membangun Karakter Bangsa. Yogyakarta: UNY Press. 
Riya Reza, Ismail, Yuliatin, Pengaruh Penerapan Model Pembelajaran Mindmapping...

Siti Marhamah Rabiatul adawiah. 2017.Pengaruh penerapan model pembelajaran Mind Mapping terhadap hasil belajar siswa kelas VIII pada mata pelajaran PPKn di SMPN 1 Batulayar.Skripsi SI. Universitas Mataram. 